\title{
A study profile of deaths due to carbamate poisoning and its management in Hyderabad region
}

\author{
Mohammad Liyaqat Shareef ${ }^{1}$, K. Rajender Kumar ${ }^{2 *}$ \\ ${ }^{1}$ Associate Professor, ${ }^{2}$ Professor, ${ }^{1-2}$ Dept. of Forensic Medicine, ${ }^{1}$ Ayaan Institute of Medical Science, ${ }^{2}$ Gandhi Medical College, Hyderabad, \\ Telangana, India.
}

*Corresponding Author: K. Rajender Kumar

Email: liyaqatshareef@gmail.com

\begin{abstract}
Introduction: Poisoning with various substances is an important cause of death and disability worldwide. The types of poisons that are encountered in the emergency medicine departments encompass a wide range of substances. Apparently, geographic location, sociodemographic factors, ease of availability of poisons and many other cryptic factors contribute to the wide spectrum of substances that cause poisoning. Pesticides, drugs and chemicals are reported to be the most commonly used poisons in India. Management of poisoning is quite challenging for the health care professionals globally. Factors such as the uncertainty in the identification of allegedly consumed poison, varied clinical features and the need for timely access to specific information for treatment, complicates poisoning management.

Aim: This study was therefore conducted to explore the clinical features, management and outcomes of poisoning cases reporting to a tertiary care centre in Hyderabad.

Methods \& Results: The present study was undertaken to evaluate the pattern of poisoning deaths in Hyderabad region of Telangana. The Paper presents the study of 271 cases of poisoning during the span of three years from 01/04/2016 to 31/03/2018. Out of 1841 Post mortem examination done during the study period 271 cases were of poisoning. Among the poison cases carbamate insecticide accounted for 21 cases $(7.74 \%)$. The cases were then analyzed on various parameters in the pro forma prepared for this purpose. We concluded that majority of victims were married, different religions males from rural area and low socioeconomic group. The incidence of poisoning was more common during 21-30years of life. Suicidal cases were more common than accidental cases. Few case of homicidal poisoning was detected in present study, chemical analysis of viscera done in cases.

Conclusion: Carbamate poisoning was the most common type of poisoning. Several chemicals like Lannate, Baygon, Temik, Sevian and Isolanwere used with suicidal intention. There were no casualties. Timely management of poisoning according to evidence based guidelines potentially minimises morbidity and mortality due to poisons and helps improve patient outcomes.
\end{abstract}

Keywords: Tachycardia, pulmonary oedema Lannate, Baygon, Temik, Sevian and Isolanwere.

\section{Introduction}

Due to rapid development in science and technology and vast growth in the Industrial and agricultural sector, the incidence of poisoning is spreading like a wild fire. A number of chemical substances, which are, developed to save the agriculture products from rodents and pests, so as to protect the human beings from starvation, are infact, themselves proving to be man-eaters. ${ }^{1,2}$ Death as a reason of poisoning/drug abuse is of enormous medical, legal and social significance. Due to easy availability of poisons and low cost, many people prefer it for the purpose of suicide, as poisons leading to peaceful death. Even though the advanced medical treatment and awareness, the poisoning cases are increasing day by day.

The incidence of poisoning in India is among the highest in the world. It is estimated that more than 50,000 people die every year from toxic exposure. According to the National Poisons Information Centre, New Delhi, analysis of poisoning calls showed that the highest incidence of poisoning was due to household agents $(44.1 \%)$ followed by drugs $(18.8 \%)$, agricultural pesticides (12.8\%), industrial chemicals $(8.9 \%)$, animals bites and stings (4.7\%), plants (1.7\%), unknown (2.9\%) and miscellaneous groups (5.6\%). The commonest cause of poisoning in developing countries is pesticides which includes organophosphates, carbamates, chlorinated hydrocarbons, pyrethroids and aluminium or zinc phosphide. The reason behind this upsurge is the agriculture based economics, poverty, unsafe practices, illiteracy, ignorance and easy availability of highly toxic pesticides. Majority of victims of poisoning are from lower socio economic status. ${ }^{2}$

The carbamate is a group of insecticides derived from carbamic acids. They have a broad spectrum uses as agricultural and house hold garden insect sides. Sevin Baygon and Lannate are most commonly used insecticides.

Carbamate is the predominant cholinesterase inhibitor, but the cholinesterase inhibitors are the reversible inhibitors. They cause this effect by reversible carbamylation of the enzymes acetyl cholinesterase, allowing accumulation of acetylcholine as with the other organophosphates. The carbamates are absorbed by including inhalation, ingestion, and dermal absorption. 3,4

Unlike the organophosphates, the carbamates poorly penetrate the central nervous system. Thus; the clinical presentation of carbamate poisoning resembles that of organophosphate poisoning with the exception of prominent central nervous system effects, such as convulsions. Convulsions are uncommon with carbamate insecticides.

Serum and red cell cholinesterasevalues are not reliable in capturing the diagnosis of carbamate poisoning as they are with the organophosphates, for enzyme activity returns to normal with in few hours, A patient may show symptoms 
in the emergency department $6 \mathrm{hrs}$ after exposable but esterase levels may have already returned to normal. ${ }^{5}$

Mortality rates depend upon amount and type of compound, condition of patient on arrival at hospital, delay in diagnosis and treatment, and respiratory management. There was always correlation with type of compounds, prehospitalization period, and the type of management, and they are useful for preventing the mortality rate in developing countries such as India. ${ }^{5}$ Treatment includes early resuscitation with oxygen, airway protection, intravenous fluids, muscarinic antagonist such as atropine, and acetyl cholinesterase activator such as PAM. ${ }^{4}$ Gastric lavage could have a role but should only be undertaken once the patient is stable. Patients must be carefully observed after stabilisation for changes in atropine needs, worsening respiratory function because of IMS, and recurrent cholinergic features occurring with fat-soluble organophosphorus compounds. ${ }^{6}$ So, in a light of increased use of OP compounds and its various applications, it is worth to study in detail the various clinical and biochemical aspects of OP poisoning.

Morphine, reseprine, pehnothaizines, organoch olridiazepoxide are not used in carbamate poisoning. In the critical patients with respiratory arrest and pulmonary oedema, sophisticated critical management with pulmonary consultation is necessary. General supportive care is indicated.

The present study was undertaken to identify the death profile caused by carbamate insecticide poisoning and its management in Hyderabad region, Telanagana, India.

\section{Materials and Methods}

\section{Place of the study and study period}

Cases of suspected poisoning with organophosphate and carbamate compounds were studied amongst the dead bodies that have come for post-mortem examination to the Department of Forensic Medicine, Gandhi Hospital, and Hyderabad in association with Ayaan institute of medical Sciences, Hyderabad during the period between January 2016 to December 2018.

A through postmartem examination was done, on each case. The entire case histories of the patients from hospital records and from the patient's relatives were studied to learn the antimortem behaviour of the patients. After the postmortem examination the tissue were submitted to Histopathological examination, all the viscera were sent to the Director, Forensic Science Laboratory, Govt. of Telanagan for necessary toxicological analysis.

The diagnosis of poisoning with organophosphate and carbamate in the cases under study was made on the basis of clinical history, post-mortem examination findings and report of chemical analysis. However in these cases, where the post-mortem appearance and clinical history were clearly and unequivocally indicating that the cause of death was due to pesticide poisoning, much reliance was not attached to negative chemical analysis report.

An attempt has been made to ascertain the manner of death in case of each, taking into consideration the history given, the age of the deceased, the nature of the poison responsible for the death and other available information.

\section{Routes of administration}

In all the cases whether suicidal, Homicidal or accidental the poison is administered orally. Only in some cases poisoning resulted from accidental contamination of the skin while spraying, Poisoning through respiratory tract also can occur due to inhalation of poison while spraying even while spraying with protected cloths.

\section{Physical Examination}

On physical examination the presence of diaphoresis (Increased sweating), meiosis, Lacrimation, excessive salivation, Reparatory distress with wheeze, disturbances in consciousness or orientation, Rhonchi and rales, Bradycardia or Irregular heartbeat, weakness or paralysis, extension plantar responses and muscle fasciculation may be noted.

\section{Postmartem appearances}

No specific anatomic changes are found in acute poisoning. The changes are suggestive of asphyxia, the appearances are external or internal.

Externally the face is cyanosed there is froth at the nose and mouth, and the froth may be blood strained. Kerosene like smell may be perceived.

Internally the stomach contains greenish oily substances used as diluents and their kerosene like smell easily perceived. The contents of the stomach are blood stained, mucosa is congested and sub mucosal patecheal haemorrhages and hyperacimea are seen. The other post mortem findings are pulmonary oedema, capillary dilation, patecheal haemorrhages and hyperaemia of lungs, brain and other organs. In delayed paralysis of extremities induced by parathion, malathionand other compounds the findings are demylenation of ascending and descending spinal tracts with degeneration of motor horn cell. Carbamate compounds resist the decomposition and they have been detected in highly decomposed bodies that have been between 3-7 days prior to post-marten examination.

Since alcohol makes the smell and these compounds have been used with alcohol for homicidal purposes the viscera for chemical analysis should be preserved in saturated solution of sodium chloride in suspected cases of carbomate poisoning.

\section{Chemical analysis}

The viscera of the study group cases $(50 \%)$ were subjected to chemical analysis which revealed the presence of organophosphate compound in 36 cases, carbamate insecticide in 12 cases, no poisonous substance could be analyzed in one case and in one case final opinion is pending report of director state forensic sciences laboratory. In all the positive cases the poison was found in stomach, small intestine, liver, kidney and blood. 


\section{Method of analysis}

The viscera that are sent to forensic science laboratory are analysed mainly in two steps:

1. Extraction of the poison from the viscera

2. Identification of the poison

These two steps are briefly described here, taking example of monochrotophos (also called Azodrim), which falls founder aliphatic organophosphate poison.

\section{Extraction of organophosphate compound}

Take approximately $200 \mathrm{mg}$ of viscera in a big bowl and cut into small pieces. Make it acidic with 1:4 HCL acid. Add $100 \mathrm{ml}$ of solvent (Hexane). Stir it and wait for $10 \mathrm{~min}$. Now take the solvent into separating funnel and add few mi of distilled water. Shake well for 2-3 times. Remove the lower aqueous layer and add $2 \% \mathrm{NaOH}$ and shake it. Filter of the lower layer. Then take upper layer and wash with distilled water two times and reject the washings. Next take the upper layer and evaporate in fuming chamber. The residue is the neutral poison, which is monocrotophos in this case.

\section{Identification techniques}

Chromatography is the technique widely used for identification. This is process in which a mixture carried in a mobile phase (either liquid or gas) is separated as a result of differential distribution of the solutes between the mobile phase and a stationary liquid or solid phase around or over which the mobile is passing.

\section{Types of Chromatography}

1. Thin layer chromatography

2. Gas cromatography

3. Gas chromatography coupled with mass spectrometer (G.C.M.S)

4. High pressure thin layer chromatography (H.P.T.L.C) Among these T.L.C is the most commonly used and most sensitive technique which can detect as little as 10 $\mathrm{mg}$ of poison. HPTLC is the quicker method which takes only few minutes.

\section{Thin layer chromatography}

TLC is one of the techniques of chromatography where the stationary phase is silica gel $\mathrm{G}$ coated on a glass plate and the mobile phase is the liquid.

\section{Preparation of Glass plates (Coated with silica gel G 0.25} mm thick)

Weight about $45 \mathrm{gms}$ of Silica G (GYPSUM) and take it into mortar and thistle, add $90 \mathrm{ml}$ of distilled water makes slurry. Spread on the five glass plates. Allow to dry in air. Heat in oven at $80^{\circ} \mathrm{C}$ for $1 \mathrm{hr}$. cools it and use.

\section{Preparation of Glass tanks (Neutral)}

Using Hexane and acetone in the ratio of 8:2
2. After $1 \mathrm{hr}$ Di phenyl Cabazon (1\% prepared in $100 \mathrm{ml}$ ethyl alcohol)

\section{Procedure}

Take the evaporated neutral dish make the mass in the dish into solution with in 10 drops of acetone. Apply about 15 micro lit of the solution at the bottom of the glass plate. Also apply control sample at $2.5 \mathrm{~cm}$ away at same height. Put this plate in glass tank and run up to $15 \mathrm{~cm}$ from point of application. Then take it out of the tank, dry and spray with reagent (1). After one hour again with reagent (2). Compare the Rf values. If they are at the same height and of the same colour then it is sure that sample and control are of the same chemical nature.

\section{Histopathological Examination}

The histological examination was rather insignificant, congestion is found in all the organs. Lungs showed pulmonary oedema and congestion. Liver showed congestion, fatty degenerating haemorrhage into the inter sinusoidal spaces, and distorium of liver lobules. Kidneys showed congestion, cloudy swelling and pigmented casts. Brain gets soften with some times leads to haemorrhage into the prone with large amount of blood in the ventricles. Haemorrhage can also be due to hypertension produced by these compounds.

\section{Results}

Table 1: Showing the incidence of poisoning cases among the total number of post-mortems done in the department during the year 2018

\begin{tabular}{|l|c|c|}
\hline Cases & No of cases & Percentage \\
\hline $\begin{array}{l}\text { Total number of post- } \\
\text { mortems done }\end{array}$ & 1841 & \\
\hline Number of poisoning cases & 271 & $14.728 \%$ \\
\hline
\end{tabular}

Table 2: Showing the incidence of cases poisoned with carbamate compound among the total number of postmortems done

\begin{tabular}{|l|c|c|}
\hline Cases & No of cases & Percentage \\
\hline $\begin{array}{l}\text { Total number of post- } \\
\text { mortems done }\end{array}$ & 1841 & \\
\hline $\begin{array}{l}\text { Number of } \\
\text { carbamatepoisoning case }\end{array}$ & 21 & $1.15 \%$ \\
\hline
\end{tabular}

Table 3: Showing the number of cases with carbonates insecticide compound among the total number of poisoning cases

\begin{tabular}{|l|c|c|}
\hline Cases & No of cases & Percentage \\
\hline $\begin{array}{l}\text { Total number of poisoning } \\
\text { cases }\end{array}$ & 271 & \\
\hline $\begin{array}{l}\text { Number of carbamate } \\
\text { poisoning cases }\end{array}$ & 21 & $7.74 \%$ \\
\hline
\end{tabular}

\section{Visualising agents for organophosphates}

1. Mercury nitrate $(5 \%)$ 
Table 4: Showing the number of poisoning cases other than carbamate insecticide compound during the year

\begin{tabular}{|l|c|c|}
\hline Cases & No of cases & Percentage \\
\hline $\begin{array}{l}\text { Total number of poisoning } \\
\text { cases }\end{array}$ & 271 & \\
\hline $\begin{array}{l}\text { Number of poisoning cases } \\
\text { other than carbamate } \\
\text { compounds }\end{array}$ & 44 & $16.23 \%$ \\
\hline
\end{tabular}

Table 5: Showing the incidence of cases of carbamate insecticide compound poisoning cases in the last 3 years

\begin{tabular}{|c|c|c|c|}
\hline Year & $\begin{array}{c}\text { Total number of } \\
\text { post-mortems } \\
\text { done }\end{array}$ & $\begin{array}{c}\text { No. of carbamate } \\
\text { compound } \\
\text { poisoning cases }\end{array}$ & Percentage \\
\hline 2016 & 1866 & 06 & $0.23 \%$ \\
\hline 2017 & 1833 & 11 & $0.65 \%$ \\
\hline 2018 & 1841 & 21 & $1.15 \%$ \\
\hline
\end{tabular}

Table1 Shows that the suspected poisoning cases formed nearly $15 \%$ of total postmartems during the year 2018.Table $21.15 \%$ of the total postmartems or the cases poisoned with carbamate compounds.

It is clear from Table $3 \&$ Table 4 , that among the total number of suspected poisoning cases $7.74 \%$ cases are those poisoned with carbamate insecticide compounds.

Table 5 Shows the incidence of cases of poisoning other than carbamate insecticide compounds, which include alcohol and endosulphan, Diazapam, Herbal poisons and corrosive poisons during the year 2018. It is about $16 \%$.

Table shows the gradual increase in the incidence of carbamate insecticide poisoning cases which was $0.3 \%$ in the year 2016 and $1.15 \%$ in the year 2018 .

\section{Sex incidence}

Table 6: Showing the sex incidence of these cases

\begin{tabular}{|l|c|c|}
\hline Sex & No. of cases & Percentage \\
\hline Male & 31 & $62 \%$ \\
\hline Female & 19 & $38 \%$ \\
\hline
\end{tabular}

The above table shows that $62 \%$ of cases were males and $38 \%$ of cases were females in the series of cases $i$ have studied during the period January 2016 to December 2018. This clearly shows that the incidence in the males higher than females.

\section{Age incidence}

Table 7: Showing the Age incidence from the study group cases

\begin{tabular}{|c|c|c|}
\hline Age group & No. of cases & Percentage \\
\hline $0-10$ yrs & --- & - \\
\hline $11-20$ yrs & 13 & $26 \%$ \\
\hline $21-30$ yrs & 20 & $40 \%$ \\
\hline $31-40$ yrs & 07 & $14 \%$ \\
\hline $41-50$ yrs & 06 & $12 \%$ \\
\hline $51-60$ yrs & 04 & $08 \%$ \\
\hline 61 and above & - & - \\
\hline
\end{tabular}

From the above table it is clear that the majority of cases are in the third decade. No cases reported below 10 yrs of age and above 61 yrs of age. From the above data even though it is apparent that more suicides are committed by the younger persons, it is also striking that a large number of elder persons have also fallen victims to this evil.

\section{Religion incidence}

Table 8: Showing the religion incidence from the study group

\begin{tabular}{|l|c|c|}
\hline \multicolumn{1}{|c|}{ Religion } & No. of cases & Percentage \\
\hline Hindu & 44 & $88 \%$ \\
\hline Muslims & 06 & $12 \%$ \\
\hline Christians & - & - \\
\hline
\end{tabular}

The above shows that the incidence in Hindus is relatively high due to their agricultural background which is less in Muslims and Christians. Because of the agricultural background the insecticides are easily available at hand and hence more incidence among Hindus.

\section{Products and solvents used}

Tik-20 (Diazenon) and parathion (Folidol) are the products commonly used. They are mixed with aromax which gives the smell of kerosene. Tik-20 is mostly used because it iscommonly used in the house to kill bugs and as readily available. Among the carbamatebaygon spray (Propokur) is commonly used as household and garden insecticide.

\section{Routes of Administration}

In all the cases oral route was used to administer the poison. Skin contamination is not found because spraying problems are not present in the city.

\section{Sign and Symptoms}

Out of 50 cases under study 8 cases brought dead, hence no sign and symptoms could be noted. For the remaining 42 cases where the hospital records were available, the clinical data were recorded.

Table 9: Showing the symptoms among the cases studied

\begin{tabular}{|l|c|c|}
\hline Symptoms & No. of cases & Percentage \\
\hline Unconsciousness & 38 & $90.47 \%$ \\
\hline Vomiting & 04 & $9.42 \%$ \\
\hline Semi consciousness & 04 & $9.42 \%$ \\
\hline Convulsions & 28 & $66.06 \%$ \\
\hline Froth at mouth \& nostrils & 26 & $61.09 \%$ \\
\hline
\end{tabular}

Table 10: Showing the frequency of Signs among the cases studied

\begin{tabular}{|l|c|c|}
\hline \multicolumn{1}{|c|}{ Signs } & No. of cases & Percentage \\
\hline Neurological signs & & \\
\hline Constricted pupils & 36 & $85.71 \%$ \\
\hline Dilated pupils & 02 & $4.76 \%$ \\
\hline Fasciculations & 05 & 11.9 \\
\hline Respiratory signs & & \\
\hline Signs of pulmonary oedema & 37 & $88.00 \%$ \\
\hline Cyanosis & 15 & $11.9 \%$ \\
\hline
\end{tabular}




\begin{tabular}{|l|c|c|}
\hline Consolidation & 04 & $9.52 \%$ \\
\hline Cirulatory signs & & \\
\hline Peripheral circulatory failure & 04 & $9.52 \%$ \\
\hline Tachycardia & 32 & 76.17. \\
\hline Hypertension & 03 & $7.14 \%$ \\
\hline Hypotension & 12 & $28.57 \%$ \\
\hline
\end{tabular}

From the above it is observed that unconsciousness, stupor $(90.47 \%)$, vomiting $(9.42 \%)$, convulsions $(66.00 \%)$ and froth at mouth and nostrils $(61.99 \%)$ and the common symptoms whereas constricted pupils $(85.71 \%)$, pulmonary oedema $(88.00 \%)$, Tachycardia $(76.17 \%)$, hypotension $(28.57 \%)$ are the common signs noted in this series of cases who were treated in the hospital and where the hospital records were available.

Constricted pupils are the most important signs. However, it may not be seen in every case. In this series two cases were studied who had dilated pupils. This is probably due to excessive amount of alcohol taken along with poison in these cases.

\section{Fatal doses}

Fatal dose varied from half a spoon to one ounce. It could not be given in mg. In most cases as the poison is not found at the scene of offence and the individual may not be in a position to give the correct figure.

\section{Fatal period}

Table 11: Showing the fatal period in study group cases

\begin{tabular}{|l|c|c|}
\hline Fatal period in hours & No. of cases & Percentage \\
\hline Within half an hour & 2 & $4 \%$ \\
\hline $1 / 2-1 \mathrm{hr}$ & 16 & $32 \%$ \\
\hline 1-2 hrs & 08 & $16 \%$ \\
\hline 2-4 hrs & 06 & $12 \%$ \\
\hline 4-8 hrs & 02 & $4 \%$ \\
\hline 12-24 hrs & 03 & $6 \%$ \\
\hline 1-2 days & 03 & $6 \%$ \\
\hline 3 days and above & 02 & $4 \%$ \\
\hline $\begin{array}{l}\text { Could not be } \\
\text { ascertained(brought dead) }\end{array}$ & 08 & $16 \%$ \\
\hline
\end{tabular}

From the above table it is evident that most patients died between half to 1 hour. $64 \%$ cases died within 4 hours. The acute effects in non-fatal cases last for 6-30hrs, fading during the next $48-72 \mathrm{hrs}$ or sometimes persist for as long as 3 weeks.

\section{Discussion}

Poisoning has been regarded as a leading cause of death in rural and agricultural areas across the world. ${ }^{15}$ According to WHO $99 \%$ of fatal poisonings out of annual 251,881 occur in developing countries and particularly among agricultural workers. ${ }^{15}$ Like in present study, in most of the other studies done in rural parts of Asia, carbamate insecticidalpoisons were most commonly responsible agents for toxicity in poisoning cases. In some of the studies conducted at urban places, aluminium phosphide was reported as commonest poison followed by organophosphoruscompounds. ${ }^{16}$ In
India, opium and arsenic were very commonly used poisons in the past, but with the change of time, commonest cause of poisonings in India and other developing countries is pesticides, the reasons being agriculture based economy, poverty and easy availability of highly toxic pesticides. Another social factor, which seems related to poisonings in rural parts, is the marital status of the victim. ${ }^{17-19}$ The present study shows that over majority of the of the victims of fatal poisonings were married ones, which is almost similar to a report from another rural area. The reasons forsuch a predisposition may be related to marital conflicts, sterility or more issues and more financial responsibilities on the shoulders of the victim.

The incidence of cases of poisoning with carbamate is on increase. Poisoning hereby carbamate compound is most commonly used is baygon spray. These insecticides are easily available, cheap most effective and kill the person in a short time. Therefore the study of poisoning by carbamate compound is thought necessary and an attempt is made here.

In the present study, the incidence of carbamate compound poisoning cases is found to be $1.15 \%$ respectively of all total post-martem done $67 \%$ of all the poisoning cases. The incidence is found to be on the increase.

\section{Sex Incidence}

Incidence among the males is more than the females. ${ }^{7,8}$

\section{Age incidence}

Most of the cases occurred in the third decade. No case is reported below $10 \mathrm{yrs}$ and above 61 years of age. ${ }^{7}$

\section{Race Incidense}

More number of cases has been reported among the Hindus than the Muslims. ${ }^{8}$

\section{Products commonly used}

Baygon commonly used among the organophosphate group, they are mixed with aromax which gives the smell of kerosene.

\section{Route of administration}

In the entire cases oral route was used.

\section{Signs and symptoms}

Unconsciousness (90\%), vomiting (9.4\%), and convulsions are the common symptoms. Whereas constricted pupils $(85 \%)$, pulmonary oedema $(88 \%)$, Tachycardia $(76 \%)$ and hypotension are the common signs. ${ }^{9}$

\section{Fatal dose}

Varied from half spoon to one ounce.

\section{Fatal period}

Most patients died between $1 / 2-2 \mathrm{hr}$. $64 \%$ of cases died within 4 hours. 


\section{Treatment}

Atropine sulphate is the sheet anchor of the treatment, in carbamate insecticide compounds. Large doses are tolerated. Cholinesterase reactivations are most useful and lifesaving and are now easily available in India. Several prophylactic and supportive measures studied.

\section{Post-mortem appearances}

No specific anatomic changes are found in acute poisoning. The changes are suggestive of asphyxia.

\section{Chemical analysis}

Chemical analysis revealed the presence of organophosphate compounds. The poisons are fond invariable in stomach, intestine, liver, kidney and blood. Sometimes alcohol is found along with organophosphate compound.

\section{Histopahological examination}

The findings are not significant. Histopathological examination of tissue revealed usually congestion of brain, oedema and congestion of lungs and fatty degeneration in kidneys and in some cases cloudy swelling and tubular necrosis in kidneys. ${ }^{9}$

\section{Management}

\section{Clinical presentation and treatment}

Clinical picture of carbamate poisoning is one of the cholinsgic crises as described. Treatment of carbamate poisoning includes establish of airway, stabilization of vital signs, removal of poisons gastric lavage with the usual precautions and removal of contaminated clothes and through and cleaning of skin. Activated charcoal and cathartic are indicatered in the event of ingestion. ${ }^{10}$

\section{Complications}

A few reports of delayed neurotoxicity from carbamate poisoning are noted in literature although recovery is generally completed in the majority of exposures.

\section{Atropine}

It is the drug of choice in the management of carbamate of poisoning. The doses for the adults is 0.4 to $2.0 \mathrm{mg}$ i.v. repeated every 15 to 30 minutes until signs of atropinisation (upper dry mouth) flushing and dilated pupils if pupils were originally pin point. Unlike with organophosphate poisoning large doses of atropine are not usually needed and atropinisation may be necessary for only $6-12 \mathrm{hrs}$ for the majority of patients. The exception is the critical patients. The patients preferably should be well oxygenated with the use of atropine. Children's dosage of atropine $0.05 \mathrm{mg} / \mathrm{kg}$ initially repeated as necessary at intervals similar to those for adults. The rationale for the use of atropine is the same as that with organophosphate insecticides. ${ }^{11}$

\section{Pralidoxime}

Is not indicated in the patients with pure carbamate poisoning as he cholinesterase- carbamate complex is reversible and readily dissociated. The physiologic antidote atropine, which is competitive to acetyl choline at the neuro receptor end plate, is all that is indicated until the enzyme acetyl choline esterase is able to dissociated, recover functions and metabolise over- abundant acetyl choline. Previous reports stated that pralidoxine reduced the antidotal effects of atropine in the management of carbamate poisoning especially carbaryl.

In two clinical situations pralidoxime may be given to a patient with carbamate poisoning even though it is not indicated for carbamate intoxications.

1. When a patients presents with symptoms typical of cholinesterase inhibition

2. The insecticides is either unknown or not definitely known

For serious cases is recommended for at least $24 \mathrm{hrs}$. Mild intoxications donot require such prolonged observation. As with all insecticides poisoning the patients must be observed with respect to possible toxicity from the carrier which may be methyl alcohol. ${ }^{12-14}$

Morphine, reseprine, pehnothaizines, organocholridiazepoxide are not used in carbamate poisoning. In the critical patients with respiratory arrest and pulmonary oedema, sophisticated critical management with pulmonary consultation is necessary. General supportive care is indicated.

\section{Conclusion}

Out of 271 cases of poisoning in this study, 21 cases (7.44\%) were of carbamate compound poisoning. Sex ratio (M: F) is 4:1and 21-30 yrs is the age group which commonly affected. Most of the cases belong to rural area and due to low education and awareness, majority of victims from poisoning by unknown type of poisoning. In both sexes, married persons were more involved and suicidal are commonest manner of death. Financial reason in case of married males and Domestic problem in case of married females is commonest. Education amongst the farmers of carbamate compounds regarding its proper manner of use and stringent laws in relation to its use as insecticides and pesticides in the burning need of the time to save the most commonly affected group by these toxic compounds.

\section{Source of Funding: None.}

\section{Conflict of Interest: None.}

\section{References}

1. K. S. Narayan Reddy.The Essentials of Forensic Medicine and Toxicology, 21st edition, 2002, Medical Book Company.

2. Kamath PG, Dalgi AJ, Patel BM. Diazinon poisoning, JAPI, 1964; 14, 477-81.

3. Krishna Vij. Textbook of Forensic Medicine and Toxicology Pricciples and Practice, 4th edition, 2008, Elsevier.

4. Nageshkumar G Rao. Textbook of Forensic Medicine and Toxicology, 2nd edition, 2010, Jaypee publication.

5. Ottto KR, Spate HF. Suicidal trends in urban and rural districts of Brandenburg, Psychiatry Neuro Med. Psychol, 1975; 27(4):239-46. 
6. Bardin PG, Stephen F, Johan AM, AlwynP,James RJ. Organophosphorous and carbamate poisoning. Arch Internal Med 1994; 154:1433-41.

7. Aggarwal NK and Aggarwal BBL. Trends ofpoisoning in Delhi, J Indian Acad Forensic Med 1998; 20(2): 32-6.

8. Dalal JS, Goria RK, Aggarwal AK, Thind AS and Sandhu SS. Poisoning Trends- a post mortemstudy, Journal of Indian Academy of Forensic Medicine. 1998; 20(2):27-31.

9. Dhattarwal SK and Dalal SS. Profile of Deaths Due to Poisoning in Rohtak. Haryana in the year.J Forensic Med Toxicol.1995; 14 (1):51.

10. Dhattarwal SK and Harnamsingh. Profile of death dueto poisoning in Rohtak, Haryana. J Forensic Med Toxicol. 2001; 18 (2):28-9.

11. Gargi J, Rai H, Chanana A, Raj G, Sharma G and Bagga IJS. Current Trends of Poisoning. A HospitalProfile, J Punjab Acad Forensic Med Toxicol. 2003; 3:41-5.

12. Kapila P, Sekhon HS and Mishra VK. Study of poisoning deaths in and around Shimla, Internet,Indian J Forensic Med Toxicol.2003;1 (2).

13. Murari A and Sharma GK. A comparative study ofpoisoning cases autopsied in LHMC New Delhi and JIPMER, Puducherry, J Forensic Med Toxicol.2000;19(1):18-20.
14. Nigam M, Jain AK, Dubey BP and Sharma VK. Trends of organophosphorus poisoning in Bhopal region -An autopsy based study, J Indian Acad Forensic Med. 2004; 26 (2): 62 -5.

15. Dewan A. Role and relevance of poison information centersin India. ICMR Bulletin 1997;27:43-7.

16. Gulati RS. Spectrum of acute poisonings in a Service Hospital. J Assoc Phy Ind 1995; 43:908-9.

17. Aggarwal R, Barthwal SP. Changing pattern of acutepoisonings in Eastern UP - A hospital based study. $J$ Assoc Physicians India 1995; 43:906-7.

18. DeAlwis LBL, Salgado MSL. Agrochemical poisonings in Sri Lanka. For Sci Int 1988; 36:81-9.

19. World Health Organization. In "Injury", Ed. Dr. E Krugs. World Health Org 1999; 1-5, Table 33, App.4.

How to cite this article: Shareef ML, Kumar KR. A study profile of deaths due to carbamate poisoning and its management in Hyderabad region. Indian J Forensic Community Med 2019;6(4):233-9. 